Title: Stationary Liquid Fuel Fast Reactor SLFFR — Part I: Core Design

Authors: T. Jing, G. Yang, Y. S. Jung and W. S. Yang*

Affiliation: School of Nuclear Engineering, Purdue University, IN 47907, USA

Corresponding author: Won Sik Yang

E-mail address: yang494@purdue.edu

Telephone: (765) 494-4710

Mailing address: 400 Central Dr., West Lafayette, IN 47907, USA

Total Number of Pages: 18 (including this page)

Number of Tables: $\quad 7$

Number of Figures: $\quad 7$ 


\title{
Stationary Liquid Fuel Fast Reactor SLFFR — Part I: Core Design
}

\author{
T. Jing, G. Yang, Y. S. Jung and W. S. Yang*
}

\begin{abstract}
For effective burning of hazardous transuranic (TRU) elements of used nuclear fuel, a transformational advanced reactor concept named the stationary liquid fuel fast reactor (SLFFR) has been proposed based on a stationary molten metallic fuel. A compact core design of a 1000 MWt SLFFR has been developed using TRU-Ce-Co fuel, Ta-10W fuel container, and sodium coolant. Conservative design approaches have been adopted to stay within the current material performance database. Detailed neutronics and thermal-fluidic analyses have been performed to evaluate the steady-state performance characteristics. The analysis results indicate that the SLFFR of a zero TRU conversion ratio is feasible while satisfying the conservatively imposed thermal design constraints. A theoretical maximum TRU consumption rate of $1.01 \mathrm{~kg} / \mathrm{day}$ is achieved with uranium-free fuel. Compared to the solid fuel reactors with the same TRU conversion ratio, the core size and the reactivity control requirement are reduced significantly. The primary and secondary control systems provide sufficient shutdown margins, and the calculated reactivity feedback coefficients show that the prompt fuel expansion coefficient is sufficiently negative.
\end{abstract}

Key words: fast reactor, TRU burning, zero conversion ratio, liquid metal fuel 


\section{Introduction}

In recent years, many efforts have been dedicated worldwide to exploring advanced fuel cycle options for effective transmutation of hazardous transuranic (TRU) elements of used nuclear fuels. The primary goal of the transmutation mission is to remove TRU elements from the waste stream and to fission those in nuclear systems, producing about one MW-day of energy for every gram. The transmutation performance of different systems is determined mainly by transmutation physics characteristics. Fissile isotopes are likely to fission in both thermal and fast spectrum systems, with a higher fission fraction in fast systems. However, fertile isotopes have very small fission probabilities in thermal reactor systems, and thus they are converted into higher actinides instead of being consumed by fission. In fast reactor systems, the fission probabilities of actinides increase significantly due to higher fission to capture ratios, and more fission neutrons are produced per fission. As a result, transuranic isotopes are consumed efficiently in fast reactor systems with less generation of higher actinides (Report to Congress, 2005).

The net consumption rate of TRU can be maximized by reducing the TRU conversion ratio (i.e., the ratio of TRU production to destruction) to zero by utilizing a uranium-free fuel. However, the degraded reactivity feedback of uranium-free fuels makes it very difficult, if not impossible, to develop a critical fast reactor with conventional solid fuels. Uranium-free fuels do not provide a proper prompt reactivity feedback because the Doppler feedback coefficient is almost zero or slightly positive, depending on fuel composition. At the same time, the core becomes more sensitive to an external reactivity perturbation since the delayed neutron fraction is reduced noticeably (Yang, 2008) for a uranium-free fuel. Furthermore, the burnup reactivity loss is much faster at a low conversion ratio and hence appropriate means for reactivity compensation must be employed (e.g., shorter length cycles with more frequent refueling or a large number of control assemblies). In order to overcome these difficulties in achieving very low or zero TRU conversion ratios in conventional solid fuel fast reactors, a new type of molten metallic fuel reactor concept named the stationary liquid fuel fast reactor (SLFFR) was proposed (Yang and Grandy, 2012). The feasibility of achieving a zero TRU conversion ratio with sufficiently negative prompt feedbacks was shown through preliminary core design studies for a 1000 MWt SLFFR using TRU-Ce-Co fuel, Ta-10W fuel container, and sodium coolant (Yang et al., 2013; Jing et al., 2015).

A reference point design developed in these studies has been improved to enhance the safety characteristics. Several design iterations were made to provide not only the customary safety margins in design basis events, but also to deliver superior safety performance in beyond design basis events involving multiple equipment failures or unplanned operator actions. Specifically, it was required that the double-fault accidents such as the unprotected loss of flow (ULOF), the unprotected loss of heat sink (ULOHS) and the unprotected transient over-power (UTOP) could be terminated passively (Yang et al., 2015; Jing et al., 2016a). Detailed neutronics and thermalfluidic analyses were performed to evaluate the steady-state performance characteristics. Fuel cycle performances were analyzed with detailed depletion calculations and ex-core fuel cycle models. A multi-channel safety analysis code tailored to SLFFR was developed, and various protected and unprotected accidents were analyzed. The resulting, latest core design of SLFFR is described in this paper and the companion paper (Jing et al., 2016b). The design and performance characteristics are presented in this paper, and the safety characteristics are presented in the companion paper. 
This paper is organized as follow. Section 2 describes the SLFFR core concept and Section 3 discusses the material selection and the associated design constraints. Computational tools and models are discussed in Section 4. Section 5 provides detailed descriptions of the latest SLFFR core design. Steady-state neutronics and thermal-fluidic performance characteristics as well as fuel cycle performances are discussed in Section 6. Section 7 summarizes conclusions.

\section{SLFFR Core Concept}

The fundamental concept of SLFFR is to use non-flowing liquid metallic alloy fuel of TRU in a closed fuel container (Yang and Grandy, 2012). In the initial operation, the fuel enters the reactor vessel in a solid form and then be heated to molten temperatures in a small melting heater. The fuel is contained within a closed, thick container with penetrating coolant channels as shown in Fig. 1. The fuel neither is mixed with coolant nor flows through the primary heat transfer circuit. The fuel container plays the role of conventional fuel cladding as opposed to other flowing fluid fuel concepts. The makeup fuel is semi-continuously added to the system, and thus a very small excess reactivity is required. Gaseous fission products are also removed continuously, and a fraction of the fuel is periodically drawn off from the fuel container to a processing facility where non-gaseous mixed fission products and other impurities are removed and then the cleaned fuel is recycled into the fuel container.

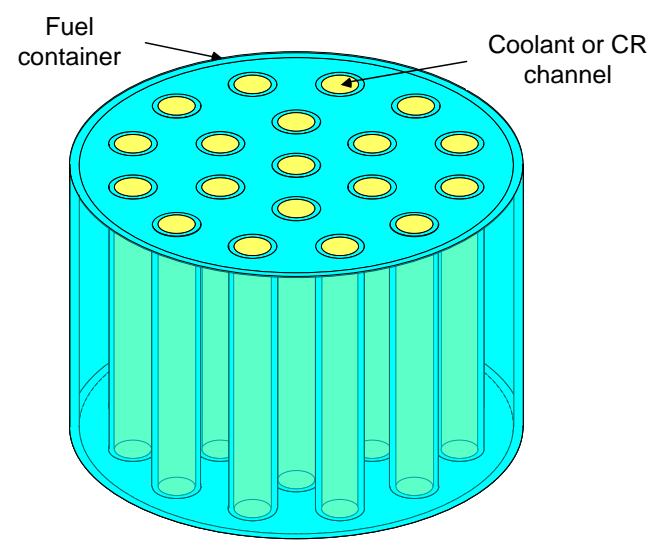

Fig. 1. Schematics of Fuel Container

The large negative reactivity feedback of molten fuel allows the use of a uranium-free fuel, and thus a zero TRU conversion ratio could be achieved. The molten fuel, which is already in its most reactive state, would also eliminate the concern about the potential for a hypothetical core disruptive accident. The continuous addition of makeup fuel and removal of gaseous fission products compensate for the reactivity loss due to fuel depletion, making the reactivity control requirements minimal. The thick fuel container and continuous fission gas removal would eliminate the traditional concern of fuel cladding integrity due to irradiation and buildup of fission gas pressure. Simple-geometry fuel container and minimal reactivity control requirements would result in a very simple reactor core system. This system can also be operated at a high power density and temperature; the high power density would lead to a compact core system, and the high operating temperature would yield a high thermal efficiency. Combination of these characteristics will provide a large potential to reduce the capital cost per unit energy produced drastically. 


\section{Material Selections and Design Constraints}

In order to have a liquid metallic TRU fuel in a closed fuel container, it is essential to use a TRU alloy with low melting temperature and a structural material of high melting temperature. Since the main constituent of TRU is plutonium, the fuel alloy was selected based on the experiences of the LAMPRE (Los Alamos Molten Plutonium Reactor Experiment) project (Hannum and Kirkbride, 1965; Andelin et al., 1967), which provides a large amount of information on the properties of liquid plutonium alloys. Plutonium-iron eutectic alloy $\left(\mathrm{Pu}_{0.9} \mathrm{Fe}_{0.1}\right)$ contained in tantalum capsules was used in the $1 \mathrm{MWt}$ test reactor LAMPRE I. However, it became clear early in the LAMPRE program that a third element was needed as a diluent to reduce $\mathrm{Pu}$ density (i.e., to increase the specific power). Cerium was selected as it forms suitable eutectics with $\mathrm{Fe}, \mathrm{Co}, \mathrm{Ni}$ and $\mathrm{Cu}$. Among various ternary alloys, $\mathrm{Pu}-\mathrm{Ce}-\mathrm{Co}$ fuel alloy has a low temperature eutectic valley with a melting point near $420{ }^{\circ} \mathrm{C}$ for a wide range of $\mathrm{Pu}$ content with a more or less constant Co content of about 25 atomic percent $(\mathrm{a} / \mathrm{o})$.

The potential for corrosion of the fuel container and release of radioactivity to the primary loop is one of the major concern of liquid fuel. In the LAMPRE project, tantalum alloys were selected for the structural material that is in contact with the liquid fuels, and corrosion tests were performed for various combinations of Pu alloy fuels and Ta alloy capsules of $0.76 \mathrm{~mm}$ thick (Kirkbride 1966; Andelin et al., 1967). Tests encompassed fuel concentrations from 5 to 8 grams $\mathrm{Pu} / \mathrm{cm}^{3}$ in contact with Ta and Ta-W alloys up to $10 \mathrm{w} / \mathrm{o} \mathrm{W}$ up to $1100{ }^{\circ} \mathrm{C}$. The test results showed that the $\mathrm{Pu}-\mathrm{Ce}-\mathrm{Co}$ alloy is much less corrosive to Ta than liquid $\mathrm{Pu}$ or $\mathrm{Pu}-\mathrm{Fe}$ alloys. It was found that carburization of tantalum vastly improved its resistance to corrosion by plutonium. Based on the experimental results, an expected average lifetime of 20 years at $700{ }^{\circ} \mathrm{C}$ was predicted for both Ta capsule containing Pu-Ce-Co and carburized Ta capsule containing liquid $\mathrm{Pu}$ (Kirkbride 1966). Since container strength is important for withstanding large thermal and pressure stresses, Ta-5W alloy was selected, which has satisfactory mechanical properties at the operating temperatures of LAMPRE $\left(750-800^{\circ} \mathrm{C}\right)$. Since no penetration of carburized Ta-5W capsules was observed, it was concluded carburized Ta-5W had at least as good corrosion resistance to $\mathrm{Pu}$ as carburized Ta.

According to these results of the LAMPRE project, TRU-Ce-Co ternary fuel was selected for this study under the assumption that the melting point of Pu-Ce-Co ternary fuel would not be increased significantly by the addition of a few percent of minor actinides (MA). Since container strength is important for withstanding large thermal stresses and preventing tube distortion during fuel freezing (although it was reported that evidence from irradiation tests indicated that melt-freeze cycling might be possible without mechanical damage), Ta-10W was selected as the fuel container material. Since tantalum is compatible with sodium up to $1000{ }^{\circ} \mathrm{C}$ (Cabot Supermetals, 2011), sodium was selected as the coolant. While no definite temperature limit was established in the LAMPRE project, a conservative limit of $700^{\circ} \mathrm{C}$ was selected for the interface temperature between fuel and coolant tubes or the container wall.

\section{Computational Methods and Models}

Neutronics analyses were performed using the fast reactor analysis code of Argonne National Laboratory. Region-dependent 33-group cross sections were generated based on the ENDF/BVII.0 library using the $\mathrm{MC}^{2}-3$ code (Lee and Yang, 2011) and TWODANT code (Alcouffe et al., 1990). Since the fuel composition for cross section generation is not known a priori, the cross section generation and the fuel cycle analysis were performed iteratively until the core 
multiplication factor at the normal operating condition is close to unity when all the control rods are out of the core. For the cross section generation at the normal operating condition, the coreaveraged fuel, container, and coolant temperatures were estimated using a single channel thermal-fluidic model. In order to calculate the fuel and structure Doppler coefficients and sodium void worth, cross sections were also generated for three perturbed states: 1) doubled fuel and structure temperatures, 2) voided flowing sodium in the core and above, and 3) doubled fuel and structure temperatures at the sodium-voided condition. For Doppler coefficient calculation, the fuel and structure temperatures were doubled since the Doppler coefficients in the SLFFR spectrum are inversely proportional to the temperature.

In the $\mathrm{MC}^{2}-3$ calculation for each core configuration, self-shielded 2082-group isotopic cross sections were first prepared for each region by numerical integration of the pointwise cross sections based upon the narrow resonance approximation. Then, a 2082-group transport calculation was conducted for the whole-core cylindrical-z (RZ) model using the discrete ordinate transport code TWODANT. Finally, region-dependent 33-group cross sections were determined by condensing the 2082-group cross sections of each region using the 2082-group TWODANT flux moment solution. Among fission products, the fuel alloy constituent Ce and gaseous fission products $\mathrm{Kr}$ and Xe were modeled explicitly. The remaining fission products were modeled using fissionable-isotope-dependent lumped fission products. Lumped fission product cross sections were generated for U-235, U-238, Np-237, Pu-238, Pu-239, Pu-240, Pu241, Pu-242, Am-241, Am-243, and Cm-244 using the yield data of ENDF/B-VII.0.

Core and fuel cycle analyses were performed in $\theta-\mathrm{R}-\mathrm{Z}$ geometries using the DIF3D (Derstine, 1984) and REBUS-3 (Toppel, 1983) codes. Core performance characteristics were evaluated for the beginning of life (BOL) and for the TRU-recycled equilibrium cycle. The BOL core is assumed loaded with the TRU fuel recovered from light water reactor (LWR) spent fuels, and the TRU fraction in the TRU-Ce-Co fuel was determined so that the multiplication factor is 1.003. The isotopic TRU composition of TRU was obtained from 10-year cooled LWR spent fuel with $50 \mathrm{GWd} / \mathrm{MT}$ burnup as shown in Table 1. For the recycled equilibrium cycle calculation, the semi-continuous fuel cycle of SLFFR was approximated by a 300-batch, 1-day fuel cycle. A single axial core zone was used for the depletion calculation, considering the mixing effect of the liquid fuel since an axial movement of the fuel with a velocity of $\sim 1.2$ $\mathrm{mm} / \mathrm{min}$ was observed in the CFD simulation, as discussed below. The TRU recovered from reprocessed SLFFR fuel was used as the primary TRU feed and the TRU recovered from the used LWR fuels was used as the makeup feed. It was assumed that the gaseous fission products $\mathrm{Xe}$ and $\mathrm{Kr}$ are removed continuously. As mentioned above, $\mathrm{Ce}, \mathrm{Xe}, \mathrm{Kr}$ nuclides were modeled explicitly while the other fission products were represented by fissionable-isotope-dependent lumped fission products.

\section{Table 1}

Isotopic Composition (wt. \%) of LWR TRU Feed

\begin{tabular}{lclclc}
\hline Isotope & Fraction & Isotope & Fraction & Isotope & Fraction \\
\hline $\mathrm{Np}-237$ & 6.64 & $\mathrm{Pu}-242$ & 5.03 & $\mathrm{Cm}-243$ & 0.01 \\
$\mathrm{Pu}-238$ & 2.75 & $\mathrm{Am}-241$ & 4.65 & $\mathrm{Cm}-244$ & 0.50 \\
$\mathrm{Pu}-239$ & 48.65 & $\mathrm{Am}-242 \mathrm{~m}$ & 0.02 & $\mathrm{Cm}-245$ & 0.04 \\
$\mathrm{Pu}-240$ & 22.98 & $\mathrm{Am}-243$ & 1.47 & $\mathrm{Cm}-246$ & 0.01 \\
$\mathrm{Pu}-241$ & 6.93 & $\mathrm{Cm}-242$ & 0.00 & $\mathrm{Cm}-247$ & 0.00 \\
\hline
\end{tabular}


The reactivity coefficients and kinetic parameters were calculated at BOL and the end of equilibrium cycle (EOEC). The effective delayed neutron fraction and prompt neutron lifetime were calculated using the VARI3D perturbation theory code (Smith et al., 2013). The coolant, fuel and structure density coefficients were also calculated using the VARI3D code. The axial and radial expansion coefficients were determined from direct eigenvalue differences between the base and perturbed conditions using the DIF3D code. The sodium void worth and the gas expansion module (GEM) worth were determined using the MCNP6 Monte Carlo code (MCNP6 user's manual, 2014) since the diffusion theory approximation overestimates the leakage effect and the available transport theory code does not have a capability to model $\theta-\mathrm{R}-\mathrm{Z}$ geometries.

Thermo-fluidic analyses were conducted using the ANSYS FLUENT computational fluid dynamics (CFD) code (ANSYS® Academic Research). Since it is not affordable to perform detailed CFD calculations for the whole core containing more than eighteen thousands coolant tubes, a three-level CFD analysis scheme was adopted. First, an appropriate mesh was determined by performing mesh sensitivity analyses using a single channel model. Then, multichannel analyses were performed to obtain the peak temperatures and liquid fuel movement for four representative regions of the core: central, middle, periphery, and annular regions. The planar layouts of the multi-channel models for these three regions are shown in Fig. 2. Finally, the whole core CFD calculations were performed using a porous media model. In FLUENT calculations, the pressure-based flow solver was used along with the standard k- $\varepsilon$ turbulence model. Both the sodium coolant and liquid fuel were modeled as liquid, and the fission gas above the fuel region was modeled as air.

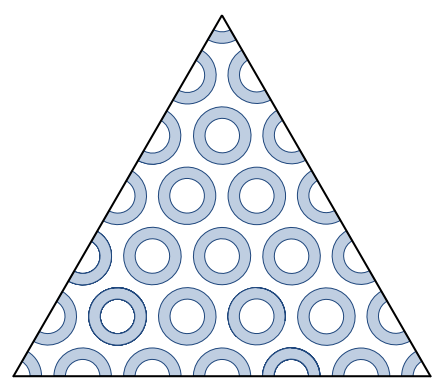

(a) Central

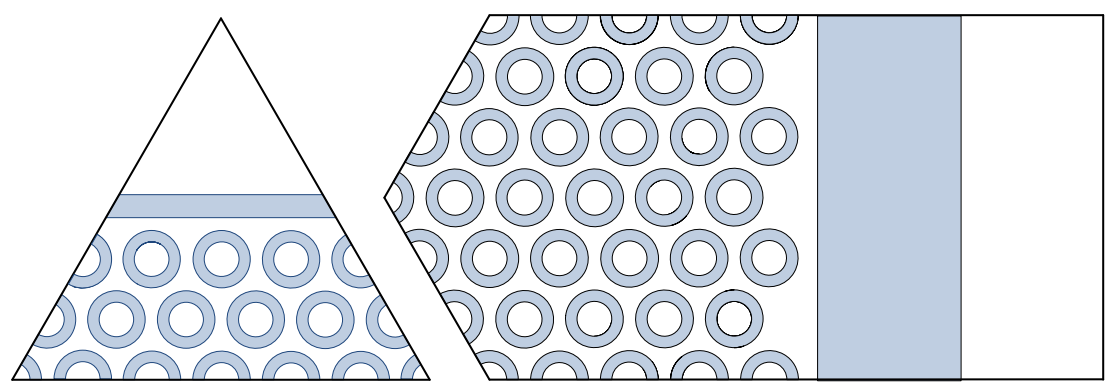

(b) Middle

(c) Periphery and Annular

Fig. 2. Planar Layouts of SLFFR Multi-channel Models for FLUENT Calculations

\section{Core Design Description}

Through various design improvements of the previous point design (Yang et al., 2013; Jing et al., 2015) to enhance the safety characteristics, a new reference core design was developed for a 1000 MWt SLFFR. The core dimensions, the number of coolant tubes, and the TRU content in TRU-Ce-Co fuel were iteratively determined to minimize the TRU loading while providing a sufficient heat transfer area from fuel to coolant so that the peak temperature at the fuel and container interface is less than the imposed limit of $700^{\circ} \mathrm{C}$. Since the melting point of $\mathrm{Pu}-\mathrm{Ce}-\mathrm{Co}$ alloy is $420{ }^{\circ} \mathrm{C}$, the coolant inlet temperature was set to $450{ }^{\circ} \mathrm{C}$. The total flow rate was determined such that the averaged coolant temperature rise across the coolant tube is $100{ }^{\circ} \mathrm{C}$. 
Figure 3 shows the radial and axial layouts of the 1000 MWt SLFFR core design, and Table 2 summarizes the main design parameters. The TRU-40Ce-25Co fuel alloy (in atom percent) is contained in a $2.5 \mathrm{~cm}$ thick cylindrical container with an inner radius of $87.5 \mathrm{~cm}$. The container height is $108 \mathrm{~cm}$, and the active core height is $100 \mathrm{~cm}$. Since the gaseous fission products are continuously removed during the operation, the fission gas plenum is only $8 \mathrm{~cm}$ high. The short fission gas plenum enhances the neutron leakage under the sodium-voided condition, and thus reduces the sodium void worth. The fuel container is penetrated by 18181 coolant tubes of $6 \mathrm{~mm}$ inner diameter and $2 \mathrm{~mm}$ thickness. The coolant tubes are arranged in a triangular lattice with a lattice pitch of $1.21 \mathrm{~cm}$. The fuel, structure and coolant volume fractions in the core are 0.386 , 0.383 and 0.231 , respectively.

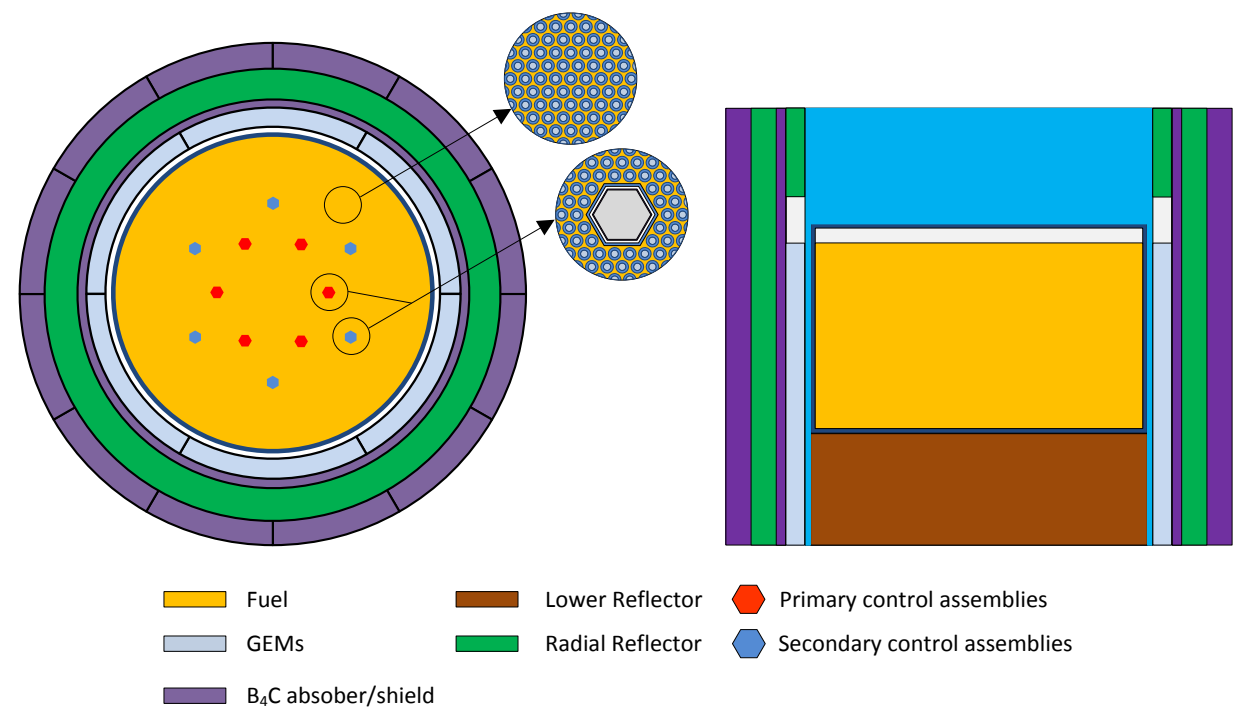

Fig. 3. Radial and Axial Layouts of 1000 MWt SLFFR

Table 2

Main Design Parameters of SLFFR Core

\begin{tabular}{llcc}
\hline Parameter & & Unit & Value \\
\hline Thermal power & & $\mathrm{MW}$ & 1000 \\
Fuel container & Inner radius & $\mathrm{cm}$ & 87.5 \\
& Thickness & $\mathrm{cm}$ & 2.5 \\
& Height & $\mathrm{cm}$ & 108 \\
& Active core height & $\mathrm{cm}$ & 100.0 \\
Coolant tubes & Number of tubes & & 18181 \\
& Thickness & $\mathrm{cm}$ & 0.20 \\
& Inner diameter & $\mathrm{cm}$ & 0.60 \\
Volume fractions & Pitch & $\mathrm{cm}$ & 1.21 \\
& Fuel & & 0.386 \\
& Structure & & 0.383 \\
Coolant & Coolant & & 0.231 \\
& Inlet temperature & ${ }^{\circ} \mathrm{C}$ & 450 \\
& Outlet temperature & ${ }^{\circ} \mathrm{C}$ & 550
\end{tabular}


Six gas expansion modules (GEMs) of $10 \mathrm{~cm}$ thickness are employed outside the fuel container to terminate the unprotected loss of flow (ULOF) accident passively without exceeding the sodium boiling temperature. GEMs were used originally in the Fast Flux Test Facility (FFTF) to enhance the negative reactivity feedback at elevated temperatures during a postulated ULOF accident (Campbell, 1986). When the core is operated under the normal condition, the sodium and gas interface is located at the same level as the top of the active core due to the balance between the gas pressure and the coolant pump head. When the pump is off, the inlet pressure drops drastically, causing the inert gas to expand until it reaches another pressure balance with the sodium coolant. The lowered sodium and gas interface enhances the radial leakage and thus introduces negative reactivity. In order to maximize the negative reactivity insertion and to avoid the possibility for the inert gas to get into the active core, the GEMs are designed so that the final elevation of the sodium and gas interface is located between the top and the bottom of the lower reflector. At the same time, a layer of $\mathrm{B}_{4} \mathrm{C}$ absorber is located outside the GEMs in order to enhance the GEMs reactivity worth by reducing the neutron reflection to the core at the sodium-voided condition. Outside the $\mathrm{B}_{4} \mathrm{C}$ absorber layer, there are steel reflectors and $\mathrm{B}_{4} \mathrm{C}$ shields.

Two separate safety-grade reactivity control systems are used in the internal region of the fuel container. Both the primary and secondary systems consist of six control assemblies. Each of them is designed to shut down the reactor from any operating condition to the cold shutdown condition. The minimum distance between two neighboring control assembly guide tubes is selected to be $26 \mathrm{~cm}$ to provide a sufficient space for control rod driving systems. The guide tube is designed in a hexagonal shape as shown in Fig. 4 to lower the peak temperature at the fuel and guide tube interface by reducing the local fuel volume fraction and thus the local heating rate. A flow separation duct is installed inside the guide tube. The coolant flow in the gap between the guide tube and the separation duct will have higher velocity than the coolant flow inside the separation duct so that the peak temperature at the guide tube and fuel interface can be minimized while maintaining the average coolant outlet temperature similar to those of the neighboring coolant tubes. The control assembly is composed of seven $\mathrm{B}_{4} \mathrm{C}$ control rods of 1.81 cm outer diameter and 90\% B-10 enrichment.

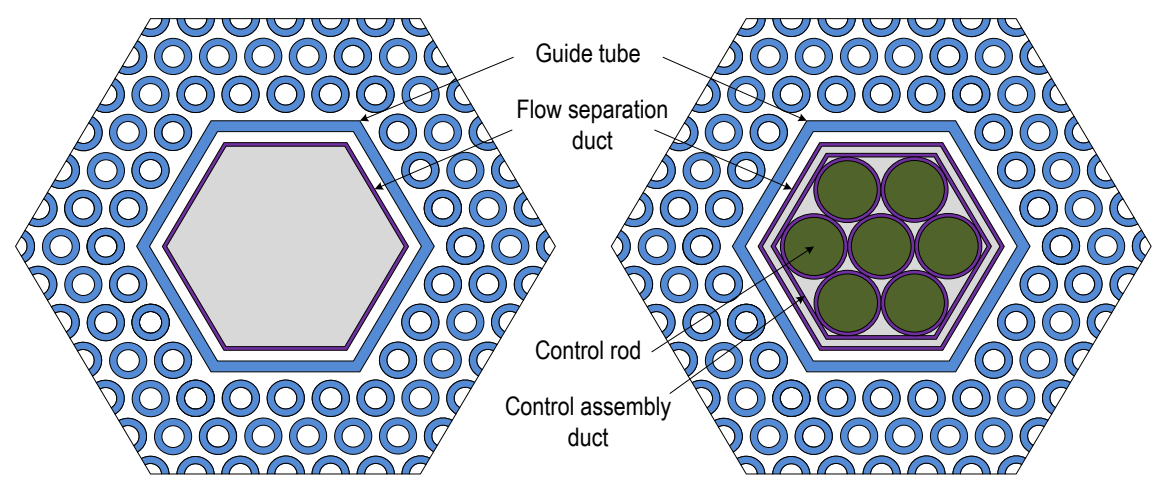

Fig. 4. Radial Layouts of Guide Tube without and with Control Assembly

\section{Performance Characteristics}


The SLFFR core performance characteristics at BOL and of the equilibrium cycle are summarized in Tables 3 and 4, respectively. Since a uranium-free fuel is used, a theoretical maximum TRU consumption rate of $1.01 \mathrm{~kg} / \mathrm{day}$ is achieved for both $\mathrm{BOL}$ and the equilibrium cycle. At BOL, the core is loaded with the TRU recovered from 10-year cooled LWR spent fuel with $50 \mathrm{GWd} / \mathrm{MT}$ burnup. The core inventory of TRU is $3541 \mathrm{~kg}$, and the daily burnup reactivity loss is $37 \mathrm{pcm}$. A daily TRU charge rate of $11.71 \mathrm{~kg}$ is required to overcome the burnup reactivity loss and maintain criticality. The charged TRU-Ce-Co fuel is composed of $24.1 \mathrm{a} / \mathrm{o}$ TRU, $51.8 \mathrm{a} / \mathrm{o} \mathrm{Ce}$, and $24.1 \mathrm{a} / \mathrm{o} \mathrm{Co}$. The power density is $413.1 \mathrm{~W} / \mathrm{cm}^{3}$ and the power peaking factor is 2.25 .

\section{Table 3}

Core Performance Characteristics at BOL of 1000 MWt SLFFR

\begin{tabular}{llcc}
\hline Parameter & & Unit & Value \\
\hline BOL core inventory & TRU & $\mathrm{kg}$ & 3541 \\
& $\mathrm{Ce}$ & $\mathrm{kg}$ & 4445 \\
& $\mathrm{Co}$ & $\mathrm{kg}$ & 867 \\
Multiplication factor & & $\mathrm{pcm} / \mathrm{day}$ & 1.00326 \\
Burnup reactivity loss & $\mathrm{BOL}$ & 37 \\
TRU consumption rate & & $\mathrm{kg} / \mathrm{day}$ & 1.01 \\
Fuel charge rate & $\mathrm{TRU}$ (Makeup feed) & $\mathrm{kg} / \mathrm{day}$ & 11.71 \\
& $\mathrm{Ce}$ & $\mathrm{kg} / \mathrm{day}$ & 8.36 \\
& $\mathrm{Co}$ & $\mathrm{kg} / \mathrm{day}$ & 2.09 \\
Core-average power density & & $\mathrm{W} / \mathrm{cm}^{3}$ & 413.1 \\
Power peaking factor & & & 2.25 \\
\hline
\end{tabular}

Table 4

Equilibrium Cycle Performance Characteristics of 1000 MWt SLFFR

\begin{tabular}{llcc}
\hline Parameter & & Unit & Value \\
\hline BOEC core inventory & TRU & $\mathrm{kg}$ & 5056 \\
& $\mathrm{Ce}$ & $\mathrm{kg}$ & 3647 \\
& Co & $\mathrm{kg}$ & 867 \\
& Fission products & $\mathrm{kg}$ & 117 \\
Multiplication factor & BOEC & & 1.00437 \\
& EOEC & $\mathrm{pcm} / \mathrm{day}$ & 1.00413 \\
Burnup reactivity loss & & $\mathrm{kg} / \mathrm{day}$ & 1.01 \\
TRU consumption rate & & $\mathrm{kg} /$ day & 33.98 \\
Fuel charge rate & TRU & $\mathrm{kg} /$ day & $(1.011)$ \\
& (Makeup TRU feed) & $\mathrm{kg} / \mathrm{day}$ & 23.54 \\
& Ce & $\mathrm{kg} /$ day & 6.08 \\
& Co & $\mathrm{kg}$ & 63.6
\end{tabular}


Core-average power density

$\mathrm{W} / \mathrm{cm}^{3}$

413.8

Power peaking factor

The TRU inventory at the beginning of equilibrium cycle (BOEC) increases to $5056 \mathrm{~kg}$ since the equilibrium cycle core contains a significantly smaller fissile fraction than the LWR TRU feed. As can be seen from the isotopic fractions shown in Fig. 5 for different TRU compositions, compared to the LWR spent fuel TRU, the Pu-239 fraction in the equilibrium cycle core is reduced by $50.2 \%$ whereas the Pu-240 fraction is increased by $50.1 \%$. The equilibrium fuel cycle requires a daily reprocessing of $63.6 \mathrm{~kg}$ of TRU-Ce-Co fuel and yields a burnup reactivity loss of $24 \mathrm{pcm} / \mathrm{day}$. A small difference between the charge rate and the reprocessing rate is due to the gaseous fission products, which are removed continuously during the operation. The daily TRU charge rate is $33.98 \mathrm{~kg}$ including a makeup TRU feed of $1.011 \mathrm{~kg}$ recovered from the LWR spent fuel. The charged TRU-Ce-Co fuel is composed of $34.4 \mathrm{a} / \mathrm{o}$ TRU, $40.6 \mathrm{a} / \mathrm{o}$ Ce and $25.0 \mathrm{a} / \mathrm{o}$ Co.

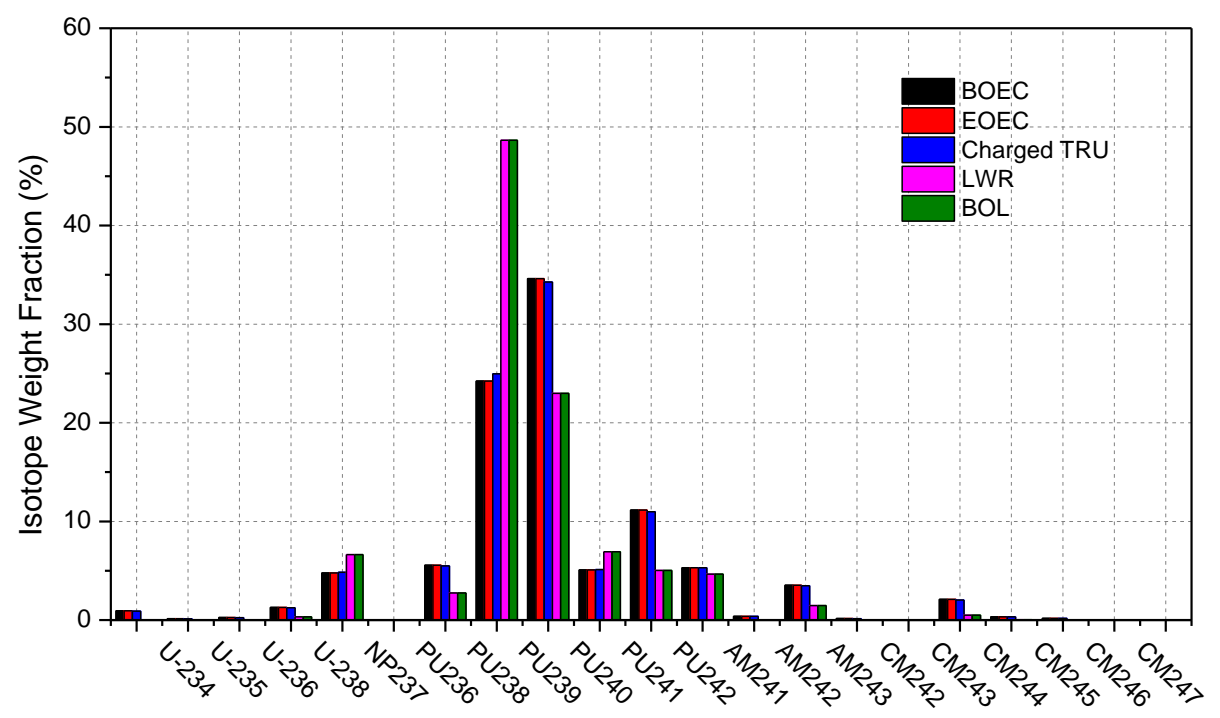

Fig. 5. Comparison of Isotopic Fractions of Different TRU Compositions

Table 5 compares the reactivity feedback coefficients and kinetics parameters of SLFFR with those of a $1000 \mathrm{MWt}$ Advanced Burner Reactor (ABR) with a zero TRU conversion ratio (Yang, 2008). The ABR concept uses TRU-40Zr metallic fuel in conventional hexagonal solid fuel assemblies. To reduce the fuel volume fraction, small diameter pins were used with grid spacers and seven tie pins. The equivalent core radius is $2.22 \mathrm{~m}$ and the active core height is $0.81 \mathrm{~m}$, and thus the active core volume of ABR is 1.3 times larger than that of SLFFR. The burnup reactivity loss of ABR is $17.8 \$$ over a relatively short cycle length of 132 effective full power days (EFPDs).

Since uranium-free fuels are used in both designs, the delayed neutron fraction is about two thirds of conventional breeder reactors and the Doppler coefficient is practically zero. However, the axial expansion coefficient of SLFFR is about 8.5 times more negative than that of the ABR because of a large thermal expansion coefficient of liquid metallic fuel as well as the $\sim 2$ times larger fuel volume fraction of SLFFR. The sodium void worth of SLFFR is slightly less positive than that of $A B R$. The radial expansion coefficient of $A B R$ is negative because axial leakage 
increases due to the diluted fuel density when the grid plate expands with an increased inlet coolant temperature. On the other hand, the radial expansion of the fuel container of SLFFR results in a slightly positive radial expansion coefficient under the assumption that the fuel height is reduced to preserve the fuel volume without fuel density change. Since ABR core is 3.3 times larger than SLFFR core, the SLFFR has significantly larger leakage, resulting in a much smaller prompt neutron lifetime in SLFFR.

The maximum reactivity worth introduced by the GEMs responding to the ULOF accident is -1.11 \$. A preliminary transient analysis of the SLFFR core design showed that the GEMs could insert a negative reactivity up to its total worth within 20 seconds after the ULOF accident initiated. The core transient was terminated passively with the peak coolant temperature of 869 ${ }^{\circ} \mathrm{C}$, which has an over $70{ }^{\circ} \mathrm{C}$ margin to the sodium boiling temperature. On the other hand, a safety analysis for the SLFFR design without GEMs showed that the ULOF accident would lead to sodium boiling at around 25 seconds into the transient. Detailed transient performance of GEMs during the ULOF will be discussed in the companion paper (Jing et al., 2016).

Table 5

Kinetic Parameters and Reactivity Coefficients

\begin{tabular}{lccc}
\hline \multirow{2}{*}{ Parameter } & \multirow{2}{*}{ Unit } & \multicolumn{2}{c}{ Value } \\
\cline { 3 - 4 } & & SLFFR & ABR \\
\hline Delayed neutron fraction & & 0.00200 & 0.00245 \\
Prompt neutron lifetime & 0.079 & 0.54 \\
Axial expansion coefficient & $\phi /{ }^{\circ} \mathrm{C}$ & -1.72 & -0.20 \\
Radial expansion coefficient & $\phi /{ }^{\circ} \mathrm{C}$ & 0.27 & -0.61 \\
Sodium density coefficient & $\phi /{ }^{\circ} \mathrm{C}$ & 0.23 & 0.19 \\
Sodium void worth & $\$$ & 7.65 & 7.95 \\
Doppler coefficient & $\phi /{ }^{\circ} \mathrm{C}$ & 0.00 & -0.01 \\
Fuel density coefficient & $\phi /{ }^{\circ} \mathrm{C}$ & -2.07 & -1.11 \\
Structure density coefficient & $\phi /{ }^{\circ} \mathrm{C}$ & 0.49 & 0.10 \\
Maximum GEM worth & $\$$ & -1.11 & $\mathrm{~N} / \mathrm{A}$ \\
\hline
\end{tabular}

Table 6 shows the evaluated control requirements and the shutdown margins of the primary and secondary control systems. Reactivity control requirements were evaluated for the BOL and EOEC conditions by taking into account the temperature and power defects including $15 \%$ overpower, the reactivity swing, and the associated uncertainties. The temperature defect was estimated by the reactivity change from the hot full power to the cold shutdown condition. The cold shutdown condition was defined for the replacement of fuel tank, although the coolant temperature is maintained above the fuel freezing temperature during a normal shutdown. The temperature defect includes the Doppler, sodium density change, axial expansion and radial expansion effects, and it was calculated by multiplying the reactivity coefficients and the temperature changes from the full power operating condition to the cold shutdown condition. The following core-averaged coolant and fuel temperatures were used in this evaluation: $450{ }^{\circ} \mathrm{C}$ for the coolant inlet temperature, $500{ }^{\circ} \mathrm{C}$ for the average coolant temperature, and $735{ }^{\circ} \mathrm{C}$ for the average fuel temperature. As the cold shutdown condition, $205{ }^{\circ} \mathrm{C}$ is used for the coolant 
temperature, considering a potential replacement of the fuel container. The liquid fuel has a volumetric expansion on freezing. To estimate the temperature defect conservatively, the fuel freezing point of $420{ }^{\circ} \mathrm{C}$ is used for the fuel temperature at the cold shutdown condition. The uncertainties include $20 \%$ of temperature defect, $50 \%$ of burnup reactivity swing and $1.0 \$$ for criticality prediction. The estimated total control requirements are $6.21 \$$ at BOL and $6.15 \$$ at EOEC.

The reactivity worth was calculated for various combinations of control assemblies inserted. Since the excess reactivity of SLFFR is very small, the primary system and secondary control systems are designed to have a similar worth. Assuming one control assembly is stuck, the reactivity worth of the primary system is $14.94 \$$ at BOL and 12.29 \$ at EOEC, and the reactivity worth of the secondary system is $10.71 \$$ at BOL and $9.53 \$$ at EOEC. The shutdown margin of the primary system is $8.72 \$$ at BOL and $6.15 \$$ at EOEC. The shutdown margin of the secondary system is $4.50 \$$ at BOL and $3.38 \$$ at EOEC. These results indicate that each of the primary and secondary control systems provides a sufficient shutdown margin.

Table 6

Control requirement, Control System Worth and shutdown margin (\$) at BOL and EOEC

\begin{tabular}{lcc}
\hline \multirow{2}{*}{ Parameter } & \multicolumn{2}{c}{ Value } \\
\cline { 2 - 3 } & BOL & EOEC \\
\hline Control requirement & 6.21 & 6.15 \\
Primary system worth & 16.30 & 12.78 \\
Secondary system worth & 11.74 & 9.96 \\
Primary system worth (with one stuck rod) & 14.94 & 12.29 \\
Secondary system worth (with one stuck rod) & 10.71 & 9.53 \\
Primary system shutdown margin & 8.72 & 6.15 \\
Secondary system shutdown margin & 4.50 & 3.38 \\
\hline
\end{tabular}

Table 7 shows the peak and averaged core temperatures obtained from the multi-channel CFD calculations for different regions of the core. The core was divided into four representative regions: central, middle, periphery, and annular regions. The central region includes 955 coolant tubes located within a radius of $20 \mathrm{~cm}$. The middle region is from the radius of $20 \mathrm{~cm}$ to $80 \mathrm{~cm}$, which consists of the 12 control assemblies and 15036 coolant tubes. The periphery region includes the four outermost rings of 2190 coolant tubes. There is also an annular region that represents the annular sodium gap of $2.5 \mathrm{~cm}$ thickness between the fuel tank and GEMs. To utilize the total coolant flow efficiently, an optimal allocation of the total coolant flow to these four regions was determined to minimize the peak temperature at the fuel and coolant tube interface. The resulting coolant inlet velocities are $20.0 \mathrm{~m} / \mathrm{s}, 15.5 \mathrm{~m} / \mathrm{s}, 11.0 \mathrm{~m} / \mathrm{s}$ and $9.7 \mathrm{~m} / \mathrm{s}$ for the center, middle, periphery, and annular regions, respectively. The corresponding peak temperatures at the fuel and coolant tube interface are $686.6{ }^{\circ} \mathrm{C}, 677.1{ }^{\circ} \mathrm{C}, 614.2{ }^{\circ} \mathrm{C}$ and 694.7 ${ }^{\circ} \mathrm{C}$ for the center, middle, periphery and annular regions, respectively, which are all below the imposed design limit of $700{ }^{\circ} \mathrm{C}$. 
Table 7

Core Temperatures with Optimal Inlet Velocities

\begin{tabular}{lccccc}
\hline Parameter & Unit & \multicolumn{4}{c}{ Value } \\
\hline Region & & Center & Middle & Periphery & Annular \\
Coolant inlet velocity & $\mathrm{m} / \mathrm{s}$ & 20.0 & 15.5 & 11.0 & 9.7 \\
Mass flow rate & $\mathrm{kg} / \mathrm{s}$ & 456.0 & 5662.9 & 575.2 & 1173.5 \\
Bulk coolant outlet temperature & ${ }^{\circ} \mathrm{C}$ & 581.1 & 575.3 & 514.2 & 451.6 \\
Peak coolant temperature & ${ }^{\circ} \mathrm{C}$ & 591.8 & 592.8 & 550.9 & 458.5 \\
Peak temp at fuel and tube interface & ${ }^{\circ} \mathrm{C}$ & 686.6 & 677.1 & 614.2 & 694.7 \\
Peak fuel temperature & ${ }^{\circ} \mathrm{C}$ & 841.7 & 798.2 & 632.8 & N/A \\
\hline
\end{tabular}

Figure 6 shows the temperature distributions of the four-representative core regions at a height of $0.6 \mathrm{~m}$ above the bottom of the core, where the peak temperature at the fuel and coolant tube interface occurs. The peak temperature at the fuel and coolant tube interface appears at the outer surface of the coolant tube in the central core region because of a relatively large power density. The peak structure temperature of the middle region appears at the outer surface of a control guide tube because of the relatively large local fuel volume fraction. The peak temperature of the fuel container occurs at its inner surface, which is slightly higher than that of the coolant tubes and closer to the design limit, but it would not be a concern since the container wall is 12.5 times thicker than coolant tubes.

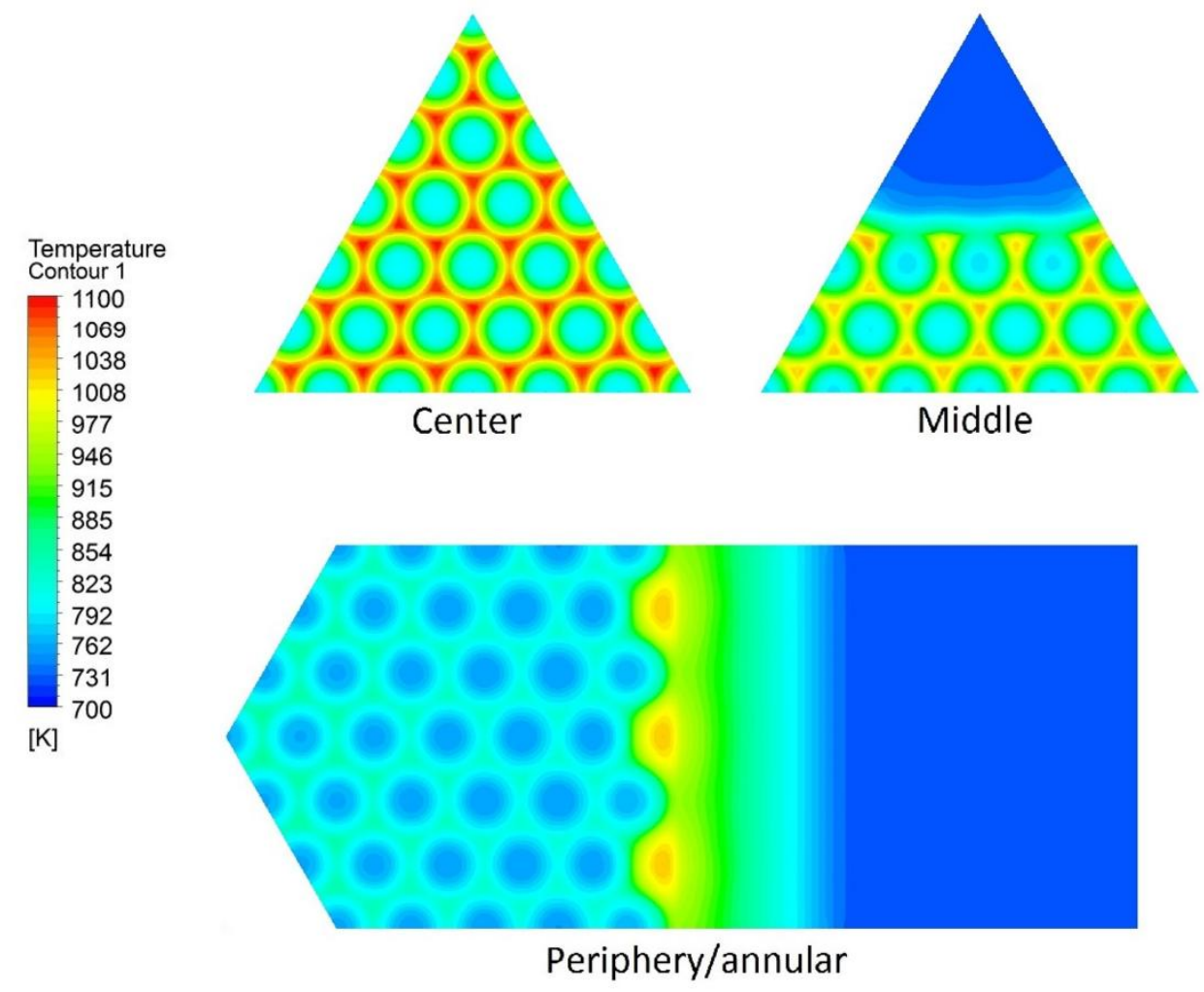

Fig. 6. Temperature Distributions of Four Representative Core Regions (at $10 \mathrm{~cm}$ above Core Mid-plane) 
The multi-channel calculations indicated an existence of natural convection or buoyancy driven flows in liquid fuel. This is consistent with the observations made in the LAMPRE I (Hall, 1962). The flow pattern of the liquid fuel affects the interface temperature between the liquid fuel and coolant tube. Fig.7 shows the liquid fuel flow pattern in the form of stream traces. The temperature is higher in a red region (i.e., an interstitial position of coolant tubes) than in adjacent yellow regions (i.e., gaps between two coolant tubes), and hence the flow is upward in the red region and downward in the yellow region. The upward and downward flows form a natural circulation flow pattern driven by the buoyancy force. The fuel movement has a speed of $\sim 1.2 \mathrm{~mm}$ per minute, indicating that the liquid fuel could be well mixed within less than one day.

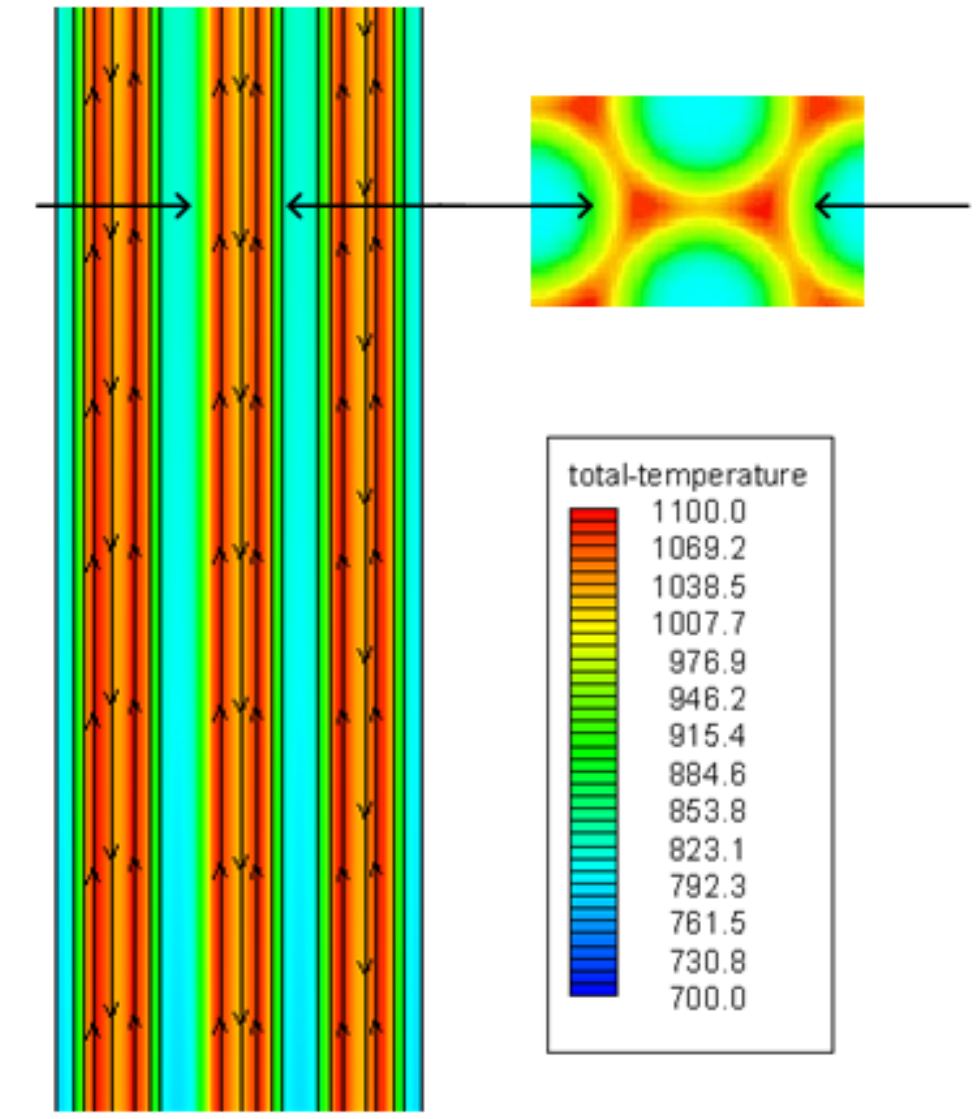

Fig. 7. Liquid Fuel Flow Pattern at the Core Center Region (Temperature in Kelvin)

To investigate the coolant temperature distribution in the core, whole-core CFD analyses were performed with porous media models. The porosity of the core (i.e., coolant flow area over the whole core area) was about 0.218 . Other parameters such as the coolant velocity and inlet temperature were consistent with those in multi-channel analyses. The region-averaged coolant outlet temperatures are $552.9{ }^{\circ} \mathrm{C}, 538.0{ }^{\circ} \mathrm{C}, 518.2{ }^{\circ} \mathrm{C}$ and $450.3{ }^{\circ} \mathrm{C}$ for the center, middle, periphery and annular regions, respectively. The region-averaged coolant outlet temperatures are lower for the central and middle regions but slightly higher for the periphery and annular regions than the bulk coolant outlet temperatures of the multi-channel models, since each of the multichannel models represents a small fraction of the corresponding region. 


\section{Conclusions}

For effective burning of hazardous TRU elements of used nuclear fuel, an innovative liquid fuel reactor concept SLFFR has been proposed based on stationary molten metallic fuel. The overall simplified concept is to use non-flowing liquid metallic alloy TRU fuel in a closed fuel container. The fuel enters the reactor vessel in a solid form, and then it is heated to molten temperatures in a small melting heater. The fuel is contained within a closed, thick container with penetrating coolant channels, and thus it is not mixed with coolant nor flow through the primary heat transfer circuit. The makeup fuel is semi-continuously added to the system, and thus a very small excess reactivity is required. Gaseous fission products are removed continuously, and a fraction of the fuel is periodically drawn off from the fuel container to a processing facility where non-gaseous mixed fission products and other impurities are removed and then the cleaned fuel is recycled into the fuel container.

A compact core design of a $1000 \mathrm{MWt}$ TRU-burning SLFFR concept was developed using TRU-Ce-Co fuel, Ta-10W fuel container, and sodium coolant. Conservative design approaches were adopted to stay within the current material performance database. Several design iterations were made to ensure that the double-fault accidents such as the unprotected loss of flow (ULOF), the unprotected loss of heat sink (ULOHS) and the unprotected transient over-power (UTOP) could be terminated passively. Two separate safety-grade reactivity control systems were introduced to provide sufficient shutdown margins. Six gas expansion modules were employed to terminate the unprotected loss of flow (ULOF) accident passively without exceeding the sodium boiling temperature. An orifice zoning approach was adopted to allocate the total flow rate effectively to the different regions of the core.

Detailed neutronics and thermal-fluidic analyses were performed to evaluate the steady-state performance characteristics. Fuel cycle performances were analyzed with detailed depletion calculations and ex-core fuel cycle models. The analysis results indicate that the SLFFR of a zero TRU conversion ratio is feasible while satisfying the conservatively imposed design constraint on the temperature at the fuel and coolant tube interface. A theoretical maximum TRU consumption rate of $1.01 \mathrm{~kg} / \mathrm{day}$ is achieved with uranium-free fuel. Both the primary and secondary reactivity control systems provide a sufficient shutdown margin. Compared to the solid fuel reactors with the same TRU conversion ratio, the core size and the reactivity control requirement are reduced significantly. The calculated reactivity feedback coefficients showed that the prompt fuel expansion coefficient is sufficiently negative. Detailed safety analysis results are presented in the companion paper (Jing et al., 2016).

\section{Acknowledgements}

This research was performed using funding received from the DOE Office of Nuclear Energy's Nuclear Energy University Programs. The authors are grateful to Dr. Shanbin Shi from the School of Nuclear Engineering at Purdue University for his contributions to the CFD calculations at the initial stage of the project.

\section{References}

Alcouffe, R. E., Brinkley, F. W., Marr, D. R. and O’Dell, R. D., 1990. 'User's Guide for TWODANT: A Code Package for Two-Dimensional, Diffusion-Accelerated, Neutral-Particle Transport," LA-10049-M, Los Alamos National Laboratory. 
Andelin, R. L., Kirkbride, L. D., and Perkins, R. H., 1967. High-Temperature Environmental Testing of Liquid Plutonium Fuels. LA-3631, Los Alamos Scientific Laboratory.

ANSYS $®$ Academic Research, Release 13.0.

Campblell, L. R. et al., 1986. Reactivity Worth of Gas Expansion Modules (GEMs) in the Fast Flux Test Facility. Trans. Am. Nucl. Soc., 53, 457.

Cabot Supermetals, 2011. Corrosion Resistance Properties of Tantalum and Alloys. http://www.cabot-corp.com.

Derstine, K. L., 1984. DIF3D: A Code to Solve One-, Two-, and Three-Dimensional Finite Difference Diffusion Theory Problems. ANL-82-64, Argonne National Laboratory.

Hall, D. B., 1962. Plutonium as a Fuel for the Los Alamos Molten Plutonium Reactor Experiment. Proc. of Plutonium as a Power Reactor Fuel, Richland, Washington, September 13 and 14.

Hannum, W. H. and Kirkbride, L. D., 1965. The Molten Plutonium Burnup Experiment. LA3384-MA, Los Alamos Scientific Laboratory.

Jing, T., Yang, G., Jung, Y. S. and Yang, W. S., 2015. An Optimized Core Design of Passively Safe Liquid Fuel Reactor SLFFR for TRU Burning. Trans. Am. Nucl. Soc., 113, 1095-1098.

Jing, T., Jung, Y. S., and Yang, W. S., 2016a. Passive Safety Characteristics of Stationary Liquid Fuel Fast Reactor (SLFFR). Proc. of PHYSOR 2016, Sun Valley, ID, May 1-5.

Jing, T., Jung, Y. S., and Yang, W. S., 2016b. Stationary Liquid Fuel Fast Reactor SLFFR - Part II: Safety Analysis. Companion paper submitted to Nuclear Engineering and Design.

Kirkbride L. D., 1966. Molten Plutonium Fuels, High Temperature Nuclear Fuels. Metallurgical Society Conference, Vol. 42, pp. 353, Gordon and Breach.

Lee, C. H. and Yang, W. S., 2011. MC ${ }^{2}-3$ : Multigroup Cross Section Generation Code for Fast System Analysis. ANL/NE-11-41, Argonne National Laboratory.

MCNP6 USER'S MANUAL, Code Version 6.1.1beta, 2014. LA-CP-14-00745, Rev. 0, Los Alamos National Laboratory.

Smith, M. A., Adams, C., Yang, W. S., and Lewis, E. E., 2013. VARI3D \& PERSENT: Perturbation and Sensitivity Analysis. ANL/NE-13/8, Argonne National Laboratory.

Toppel, B. J., 1983. A User's Guide to the REBUS-3 Fuel Cycle Analysis Capability. ANL-83-2, Argonne National Laboratory.

U.S. Department of Energy, Office of Nuclear Energy, Science and Technology, May 2005, "Report to Congress-Advanced Fuel Cycle Initiative: Objectives, Approach, and Technology Summary,"

Yang, W. S., 2008. Trends in Transmutation Performance and Safety Parameters versus Conversion Ratio of Sodium-Cooled Recycle Reactors. Proc. of 10th Information Exchange Meeting on Actinide and Fission Product Partitioning and Transmutation, Mito, Japan, October 6-10.

Yang, W. S. and Grandy, C., 2012. Stationary Liquid Fuel Fast Reactor Concept for TRU Burning. Trans. Am. Nucl. Soc., 107, 1045. 
Yang, W. S., Shi, S. and Grandy, C., 2013. Core Design Study of Stationary Liquid Fuel Fast Reactor for TRU Burning. Proc. ICAPP 2013, Jeju Island, Korea, April 14-18.

Yang, W. S. et al., 2015. Final Report on Stationary Liquid Fuel Fast Reactor. PU/NE-15/08, Purdue University. 